\title{
KAJIAN KRITIS TENTANG AKULTURASI ISLAM DAN BUDAYA LOKAL
}

\author{
M. Arsyad AT \\ Sekolah Tinggi Agama Islam (STAI) DDI Pinrang \\ Jl. Andreas Wahani No. 27 \\ Email: staiddipinrang@yahoo.co.id
}

\begin{abstract}
Abstrak:
Islam datang ke nusantara (Indonesia) tidak dapat dipisahkan dari nuansa di mana Islam itu lahir. Akan tetapi, Islam masuk ke Indonesia mampu beradaptasi dengan kebudayaan lokal. Proses persenyawaan keislaman dengan kenusantaraan, menjadikan Islam yang ada di nusantara ini, mudah diterima oleh masyarakat. Tidak ada resistensi, yang ada adalah penyambutan. Sungguhpun ada modifikasi, itu tidak lebih dari injeksi nilai-nilai keislaman dalam tradisi yang telah ada. Dalam perkembangannya, Islam nusantara dengan wataknya yang moderat dan apresiatif terhadap budaya lokal, serta memihak pada warga setempat dalam menghadapi tantangan, menyebabkan Islam diterima sebagai agama baru. Bukti nyata dari proses persenyawaan antara Islam dan budaya lokal, dapat ditemukan dalam bentuk karya Babad, hikayat, lontara, sastra suluk, mitologi. Kemudian dari segi bentuk arsitektur bangunan-bangunan atap masjid Demak yang berlapis sembilan "dari Meru" pra Islam, kemudian diganti oleh Sunan Kalijaga menjadi tiga yang melambangkan Iman, Islam, dan Ihsan. Budaya selamatan, Maulid Nabi, Yasinan, Sekaten.
\end{abstract}

\begin{abstract}
:
Islam came to archipelago (Indonesia) could not be separated from the shades where Islam was born. However, Islam that was brought to Indonesia adapted with the local culture. The process of compounding between Islamization and acculturation, made Islam in the archipelago easily accepted by society. There is no resistance, except reception. If there is a modifications, it is no more than the injection of Islamic values in a tradition that have been there. In its development, the Islamic archipelago with moderate characteristics, local culture appreciation, and taking sides to local residents in facing the challenge, causing Islam was accepted as a new religion. The real proof of the compounds between Islam and local culture, can be found in the work of the Chronicle, saga, lontara, literature, mysticism, mythology. Then, in terms of the architecture of the nineth layered roof buildings of the mosque of Demak "from Meru" in pre-Islam era, later replaced by Sunan Kalijaga to become tree roofs that symbolizes faith, Islam, and Ihsan (good deeds). Salvation culture, the Prophet's birthday, yasinan (qur'anic recitation of Yasin verses, and "sekaten", are also the real proof of the compounding.
\end{abstract}

\section{Kata Kunci: \\ Islam, Akulturasi, Budaya Lokal}

ISLAM adalah agama yang universal, sempurna, lentur, elastis dan selalu dapat menyesuaikan dengan situasi dan kondisi. ${ }^{1}$ Islam dikenal sebagai salah satu agama yang akomodatif terhadap tradisi lokal dan ikhtiläf ulama dalam memahami ajaran 
agamanya. ${ }^{2}$ Islam dibawa oleh Nabi Muhammad saw. kepada seluruh manusia dalam segala aspek kehidupan, termasuk dalam bidang sosial politik. Beliau membebaskan manusia dari kegelapan peradaban menuju cahaya keimanan. ${ }^{3}$

Universalisme Islam yang dimaksud adalah bahwa risalah Islam ditujukan untuk semua umat, segenap ras dan bangsa serta untuk semua lapisan masyarakat (al-Islam salih li kulli zamān wa makān). Ia bukan risalah untuk bangsa tertentu yang beranggapan bahwa mereka bangsa yang terpilih, dan karenanya semua manusia harus tunduk kepadanya. Risalah Islam adalah hidayah dan rahmat Allah untuk segenap manusia. ${ }^{4}$ Sebagaimana dijelaskan dalam Q.S. al-Anbiyā/21: 107.

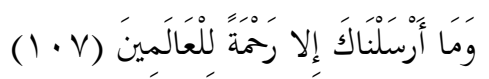

Dan tiadalah kami mengutus kamu, melainkan untuk (menjadi) rahmat bagi semesta alam. ${ }^{5}$

Demikian pula dalam Q.S. al-Furqān/25: 1.

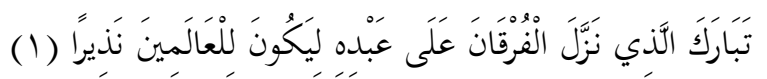

Mahasuci Allah yang telah menurunkan Furqan (Al-Qur'an) kepada hamba-Nya (Muhammad), agar dia menjadi pemberi peringatan kepada seluruh alam (jin dan manusia). ${ }^{6}$

Universalisme Islam merupakan suatu ajaran yang diterima oleh seluruh umat Islam sebagai akidah. Persoalan universalisme Islam dapat dipahami secara lebih jelas melalui sifat al-waqi'iyyah (berpijak pada kenyataan obyektif manusia). ${ }^{7}$

Ajaran universal Islam mengenai aspek kehidupan berbangsa dan bernegara akan terwujud secara substansial, tanpa menekankan simbol ritual dan tekstual. ${ }^{8}$ Ajaran Islam bukanlah agama "baru", melainkan agama yang sudah dikenal dan dijalankan oleh umat manusia sepanjang zaman, karena sejak semula telah terbit dari fitrahnya sendiri. ${ }^{9}$ Islam sebagai agama yang benar, agama yang sejati dan mengutamakan perdamaian. ${ }^{10}$ Sebagai agama rahmah li al-'älamìn, agama Islam mampu mengakomodasi semua kebudayaan dan perabadan manusia di seluruh dunia.

Meskipun Indonesia merupakan salah satu negara muslim mayoritas di dunia, namun paling sedikit mendapat pengaruh arabisasi, dibandingkan dengan negaranegara muslim besar lainnya. Dua ciri paling utama dalam kesenian Islam yakni arabesk dan kaligrafi, paling sedikit memengaruhi budaya Indonesia.

Selain itu, dalam proses Islamisasi di nusantara, penyebaran agama dan kebudayaan Islam tidak menghilangkan kebudayaan lokal dan tidak menggunakan kekuatan militer dalam upaya proses Islamisasi. Hal itu disebabkan karena proses Islamisasi dilakukan secara damai melalui jalur perdagangan, kesenian, dan perkawinan dan pendidikan.

Islamisasi juga terjadi melalui proses politik, khususnya pada pemikiran politik Soekarno yang membuka lebar bagi golongan Islam untuk mengislamkan negara dengan wilayah pengaruh yang relatif besar. ${ }^{11}$ 
Untuk mengetahui hal itu, harus dipahami dalam konteks budaya Indonesia mengalami dualisme kebudayaan, yaitu antara budaya keraton dan budaya populer di tingkat bawah (masyarakat). Dua jenis kebudayaan ini sering dikategorikan dalam kebudayaan tradisional.

\section{SEJARAH AKULTURASI ISLAM DENGAN BUDAYA LOKAL}

Menurut Kamus Besar Bahasa Indonesia akulturasi adalah percampuran dua kebudayaan atau lebih yang saling bertemu dan saling memengaruhi atau proses masuknya pengaruh kebudayaan asing dalam suatu masyarakat, sebagian menyerap secara selektif sedikit atau banyak unsur kebudayaan asing itu. ${ }^{12}$

Dari pengertian akulturasi ini, maka dalam konteks masuknya Islam ke Nusantara (Indonesia) dan dalam perkembangan selanjutnya telah terjadi interaksi budaya yang saling memengaruhi. Namun dalam proses interaksi itu, pada dasarnya kebudayaan setempat yang tradisional masih tetap kuat, sehingga terdapat perpaduan budaya asli (lokal) Indonesia dengan budaya Islam. Perpaduan inilah yang kemudian disebut akulturasi kebudayaan.

Sebelum Islam datang ke Indonesia, di Nusantara (Indonesia) telah berdiri kerajaan-kerajaan yang bercorak Hinduisme dan Budhisme, seperti kerajaan Sriwijaya dan Majapahit. ${ }^{13}$ Akan tetapi setelah proses Islamisasi dimulai sejak abad ke XIII, unsur agama Islam sangat memegang peranan penting dalam membangun jaringan komunikasi antara kerajaan-kerajaan pesisir dengan kerajaan-kerajaan pedalaman yang masih bercorak Hindu-Budha. Misalnya di daerah pesisir utara Jawa, kerajaankerajaan yang berdiri umumnya diperintah oleh pangeran-pangeran saudagar. Mereka takluk kepada raja Majapahit. Tetapi setelah raja-raja setempat memeluk agama Islam, maka mereka menggunakan Islam sebagai senjata politik dan ekonomi untuk membebaskan diri sepenuhnya dari kekuasaan Majapahit.

Setelah runtuhnya Majapahit $1520 \mathrm{M}$; di daerah pesisir proses Islamisasi berjalan intensif hingga akhirnya berdirilah kerajaan-kerajaan Islam seperti Demak, Banten dan Cirebon. Namun dalam segi pemahaman akidah Islam, tidak serta merta mantap dan melenyapkan alam pikiran filsafat lama, seperti Hindu dan Budha. Mereka memang mengucapkan kalimat syahadat, akan tetapi kenangan dan praktik kepada kepercayaan kepada Bata Guru, Batara Wisnu, Dewata Sewwa'E, dan lainnya masih tetap hidup. Di sinilah muncul kecenderungan sinkritisme. Dengan demikian, maka Islam yang berkembang di pedalaman Jawa berbeda dengan Islam yang berkembang di pesisir adalah Islam yang mobilitas sosialnya tinggi dan mengikuti perkembangan dunia Islam. Setelah kerajaan Majapahit runtuh, maka muncul penggantinya di daerah pedalaman, muncullah kerajaan Mataram Islam tahun $1575 \mathrm{M}$. Karena masa peralihan yang lama antara kerajaan Islam pedalaman dan Islam pesisir, menyebabkan mereka saling berebut pengaruh yang menyebabkan terjadinya peperangan. ${ }^{14}$

Sultan Agung (1613-1645 M) ${ }^{15}$ dari kerajaan Mataram berusaha merebut kekuasaan kerajaan pesisir sehingga unsur agama memegang peranan kembali, yakni di 
mata kerajaan-kerajaan pesisir kesultanan Mataram adalah kerajaan Islam yang sinkritisme. Di keraton kesultanan berkumpul segolongan pujangga yang mencampuradukkan antara Islam dengan Hindu, seperti terbukti pada Babad Tanah Jawi yang mengandung pencampuran Islam dengan Hinduisme. Dalam kisah babad tanah Jawi dikatakan bahwa raja-raja Jawa berasal dari Nabi Adam yang mempunyai anak Sis, seterusnya mempunyai anak Nurcahya. Lalu Nurasa, kemudian Sang Hyang Wening, seterusnya sang Hyang Tunggal, dan akhirnya dijumpai Batara Guru yang gilirannya mempunyai Batara Wisnu sebagai salah seorang puteranya yang kemudian menjadi raja jawa dengan nama Prabu Set. ${ }^{16}$

Sultan Agung memiliki perhatian yang besar terhadap kegiatan agama Islam yang dipadukan dengan budaya lokal. Dia sering berhubungan dengan ulama dari Tembayat. Perayaan grebeg disesuaikan dengan perayaan Idul fitri (Grebeg Pasa) dan Grebeg Mulud (Maulid Nabi). Selama grebeg, Gamelan Sekaten dibunyikan di halaman masjid besar. Sejak tahun 1663, tahun Saka yang berangka 1555 dan merupakan tahun Syamsiah, disesuaikan dengan tahun Hijrah yang merupakan tahun Qamariah dan lebih dikenal dengan tahun Jawa. Sebagai orang yang gemar ilmu dan filsafat, Sultan Agung mengarang kitab Sastra Gending yang berisikan mistik. ${ }^{17}$

Oleh karena itu, dalam menyikapi akulturasi budaya, analisis yang digunakan berdasarkan perspektif sejarah masuk dan berkembangnya Islam di Indonesia. Karena dalam proses Islamisasi di Indonesia tidak berjalan satu arah, tetapi banyak arah atau melalui berbagai macam pintu. Pintu-pintu itu, misalnya melalui kesenian, pewayangan, perkawinan, pendidikan, perdagangan, aliran kebatinan, mistisisme dan tasawuf. Ini semua menyebabkan terjadinya kontak budaya, yang sulit dihindari unsur-unsur budaya lokal masuk dalam proses Islamisasi di Indonesia.

Sebagai muslim, harus punya sikap kritis dalam melihat konteks akulturasi Islam dan budaya lokal dalam menelaah sejarah Islam di Indonesia. Islam itu bukanlah suatu sistem yang hanya membicarakan ke-Tuhanan saja, tetapi yang tak kalah pentingnya adalah mengandung ajaran peradaban (tamaddun) yang lengkap.

\section{AKULTURASI ISLAM DAN BUDAYA LOKAL INDONESIA}

\section{Budaya Keraton}

Perlu dipahami bahwa dalam konteks budaya Indonesia, pernah mengalami dualisme kebudayaan, yaitu budaya keraton dan budaya populer. Dua jenis kebudayaan ini sering dikategorikan dalam kebudayaan dan pengaruh Islam di kedua bentuk kebudayaan tradisional itu.

Untuk konteks budaya istana atau budaya keraton, kebudayaan dikembangkan oleh abdi dalem atau pegawai istana, mulai dari pujangga sampai pandai bangunan (arsitek). Raja berkepentingan menciptakan simbol-simbol budaya tertentu dengan tujuan untuk melestarikan kekuasaannya. Biasanya bentuk-bentuk kebudayaan yang diciptakan untuk kepentingan itu adalah mitos. Di dalam sastra kerajaan, mitos-mitos itu dihimpun, misalnya dalam babad, hikayat, dan lontara. Hampir semua mitologi yang terdapat dalam bentuk-bentuk sastra, berisi cerita-cerita ajaib tentang kesaktian 
raja, kesucian, dan kekuatan-kekuatan supranatural. Sesungguhnya pengaruh yang hendak dicapai oleh penciptaan simbol-simbol budaya mitologis kerajaan ini, adalah agar rakyat senantiasa loyal, taat, dan patuh kepada kekuasaan raja. Sebagai contoh, dalam babad Jawi, raja digambarkan sebagai pemegang "wahyu" yang dengannya dia merasa sah untuk mengklaim dirinya sebagai wakil Tuhan untuk memerintah rakyatnya. ${ }^{18}$ Raja Islam biasanya bergelar Sultan. Contohnya Sultan Agung raja kerajaan Mataram yang bergelar khalifatullah atau wakil Tuhan di tanah Jawa. ${ }^{19}$ Selain itu, Sultan Agung juga menggunakan gelar susuhunan. Ia adalah raja Mataram yang pertama kali menggunakan sebagai gelar tersebut. Ia dikenal sebagai raja yang banyak memberi perhatian terhadap perkembangan Islam di Jawa. ${ }^{20}$

Raden Fatah, raja Islam pertama di Jawa adalah santri dari Pesantren Ampel Denta. Sunan Gunung Jati, Sultan Cirebon pertama dididik dalam pesantren Gunung Jati oleh Syekh Nurul Jati. Dalam struktur kekuasaan kerajaan bercorak Islam, yang menjadi penguasa tertinggi adalah raja yang diberi gelar sultan. Pada awal berdirinya beberapa kerajaan Islam belum memakai gelar sultan. Gelar-gelar yang dipakai berkaitan dengan gelar keagamaan seperti Maulana Hasanuddin, Maulana Muhammad yang menjadi raja Banten. Raden Patah, raja Demak dan Raden Samudera, raja Islam Banjar yang pertama. ${ }^{21}$

Di antara kerajaan di Sulawesi Selatan, kerajaan Wajo dipimpin raja yang bergelar Arung Matoa Wajo yang tidak diwariskan. Arung Matoa diangkat oleh badan yang disebut Arung Enneng'E (raja yang enam) atau Petta Enneng'E (enam yang dipertuan menjadi kepala negara yang dihormati dan dituankan di seluruh tanah Wajo). Lembaga ini, Arung Matoa dan Arung Enneng'E biasanya disebut Petta Wajo (yang dipertuan di Wajo). ${ }^{22}$

Selain mitos, budaya keraton juga memproduksi sastra mistik. Bila mitos ditujukan untuk mengukuhkan kekuasaan raja dan loyalitas rakyat, maka sastra mistik ditujukan untuk memberikan pengetahuan tentang kosmologi. Dalam hasanah mistik Jawa misalnya, dikenal sastra suluk yang menggambarkan konsep tentang sangkan paraning dumadi, yaitu suatu konsep tentang realitas kosmos dan kedudukan manusia di dalamnya. Sastra-sastra mistik kerajaan semacam ini seolah-olah memberikan pesan, agar manusia dapat memahami dunianya dalam konteks kosmologi keraton. ${ }^{23}$

Dua produk budaya yang bersifat mistis yang diciptakan oleh keraton samasama bertujuan untuk mempertahankan status quo kerajaan. Mitologi dan mistisisme keraton dalam rangka meligitimasikan kekuasaan mutlaknya dengan cara menciptakan silsilah genealogis, bahwa dia adalah keturunan dewa. Tapi anehnya, pada saat yang sama dia juga mengklaim sebagai keturunan para Nabi.

Yang menarik adalah bahwa ternyata betapa pun dalam kebudayaan keraton dominasi Hinduisme atau pun filsafat pra-Hindu terasa sangat kuat, namun pengaruh Islam pun meninggalkan bekas yang cukup kuat. Dalam silsilah genealogis rajaraja Jawa, terlihat banyak sekali konsep yang dipinjam dari warisan mistik Islam. Meskipun raja Jawa diklaim sebagai keturunan para dewa suatu indikasi yang menunjukkan pengaruh Hinduisme, tapi akar genealogis teratas dilukiskan dalam 
konsep nur-roso dan nur-cahyo. Menurut silsilah keraton, nur-roso dan nur-cahyo inilah yang melahirkan Nabi Adam AS, dan dewa-dewa sebagai kakek moyang raja-raja Jawa. Setelah nur-roso dan nur-cahyo, konotasinya bersifat Jawa, tapi mengingatkan kita pada konsep Nur-Muhammad dalam khasanah mistik Islam. Jelas bahwa dari contoh ini diambil kesimpulan bahwa banyak budaya mistik Islam dipinjam oleh kebudayaan keraton Jawa, walaupun dipakai untuk melegitimasi kosmologinya sendiri. ${ }^{24}$

Hal yang perlu mendapat perhatian adalah bahwa budaya keraton di luar Jawa memiliki konsep yang lebih dekat dengan gagasan Islam. Di Aceh, raja memiliki sebutan sebagai al-Malik-al-'adl. Ini berarti pula bahwa berbeda dengan kebudayaan keraton Jawa yang lebih menekankan konsep kekuasaan dan kebudayaan. Keraton di luar Jawa lebih menekankan konsep keadilan. Karena konsep kekuasaan mutlak yang diterapkan di dalam keraton Jawa, timbul dilema pertentangan antara Jawa dengan Islam ketika proses Islamisasi nusantara. Salah satunya yang terpenting adalah para persoalan tentang sosial kemasyarakatan. Konsep Jawa mengenai ketertiban sosial lebih didasarkan pada konsep kekuasaan mutlak raja, sementara Islam mengajarkan bahwa ketertiban sosial masyarakat terjamin bila peraturan-peraturan syari'ah ditegakkan. Di sinilah letak perbedaan yang sering menimbulkan ketegangan.

Contoh tentang konflik antara Syekh Siti Jenar dengan seorang raja dari Demak. Siti Jenar dikenal sebagai seorang wali yang cenderung mistik yang sangat kuat. Jalan tarikat yang ditempuhnya sering menimbulkan ketegangan dengan ketentuan-ketentuan syariah yang baku. Sering dengan kekuatan mistiknya menyebabkan dia meremehkan hukum-hukum yang sudah diadopsi oleh kerajaan sehingga Siti Jenar dihukum mati dengan cara dibakar. ${ }^{25}$

Dari uraian mengenai budaya keraton dalam menghadapi pengaruh budaya Islam cenderung bersifat defensif. Kaum bangsawan dan kalangan istana menerima pengaruh-pengaruh tertentu dari Islam selama pengaruh-pengaruh tersebut diadopsi untuk status quo kekuasaan Jawa. Inilah sikap yang tampak menjadi karakteristik budaya keraton Jawa dalam berhadapan dengan Islam, suatu sikap yang berbeda diambil oleh budaya keraton di luar Jawa yang cenderung menerima sepenuhnya pengaruh Islam sebagai unsur pembentukannya yang utama.

\section{Budaya Populer (Masyarakat Biasa)}

Sama halnya di dalam budaya keraton, dalam budaya populer (budaya rakyat) juga dikenal adanya cerita-cerita mitologis dan mistis. Cerita mengenai wali songo menjadi bukti hal ini. Sebagai contoh Sunan Kalijaga, dalam kisah-kisah dari pantai Utara Jawa begitu terkenal sampai orang memercayai adanya sebuah batu bekas sujudnya. Kisah semacam ini adalah salah satu contoh dari mitologi Islam di Jawa. ${ }^{26} \mathrm{Ce}-$ rita-cerita mengenai penyebaran Islam dalam masyarakat, banyak sekali diwarnai oleh mitologi-mitologi. Adanya kiyai-kiyai sakti yang dapat shalat di Mekkah dalam waktu sekejap untuk kemudian pulang kembali ke pesantrennya. 
Meskipun pengaruh budaya populer Islam menjadi berwarna mistis, tapi pada perkembangan berikutnya kebudayaan populer di Indonesia banyak sekali menyerap konsep dan simbol-simbol Islam, sehingga seringkali tampak bahwa Islam muncul sebagai sumber kebudayaan yang penting dalam kebudayaan populer Indonesia.

Yang juga sangat penting untuk diperhatikan betapa pengaruh Islam sangat terasa dalam bidang keilmuan di lingkungan kebudayaan popular kita. Dalam ilmu pengetahuan tradisional yang sering dikenal dengan istilah "ngelmu", konsep Islam tampak jelas sekali, yaitu mulai dari pembahasan tentang kosmologi sampai adab bersuami isteri. ${ }^{27}$

Demikian juga dalam ekspresi ritual, dan sosial dikenal upacara "tabut" (di Sumatera) untuk memperingati maulid Nabi, begitu juga di Jawa dengan upacara "Sekatennya". Seni musik tidak kalah pentingnya, seperti: qasidah rebana, dan gambus di daerah Jawa, Sumatera dan Sulawesi. ${ }^{28}$

Islam nusantara disebut sebagai suatu entitas, karena memiliki karakter yang khas yang membedakan Islam di negara lain karena perbedaan sejarah, dan perbedaan geografis dan budaya yang dipijaknya. Islamisasi di Jawa berjalan secara dialogis dan relatif kompromistis. Di luar Jawa, suku-suku yang masuk Islam sepertinya harus memilih secara tegas antara Islam sebagai identitas baru dan melepas budaya dan kepercayaan lokalnya atau sama sekali menolaknya. ${ }^{29}$ Selain itu Islam yang datang ke nusantara memiliki strategi dan kesiapan tersendiri, antara lain: Pertama, Islam datang dengan mempertimbangkan tradisi. Tradisi yang berseberangan tidak dilawan, tetapi diapresiasi, kemudian dijadikan sarana pengembangan Islam. Kedua, Islam datang tidak mengusik agama atau kepercayaan apapun, sehingga bisa hidup berdampingan. Ketiga, Islam datang mendinamisir tradisi yang sudah usang, sehingga Islam dapat diterima sebagai agama. Keempat, Islam menjadi agama yang mentradisi, sehingga orang tidak bisa meninggalkan Islam dalam kehidupan mereka.

Dengan fakta sejarah tersebut, maka dapat disaksikan agama Islam dipeluk atau dianut oleh seluruh masyarakat nusantara. Bagi mereka yang memperoleh pengetahuan keagamaan yang memadai, mereka menjadi Islam santri yang taat. Sementara bagi mereka yang kurang memperoleh pengetahuan keagamaan, disebut dengan Islam abangan, mereka secara ritual tidak taat, tetapi mereka kukuh memegang tradisi, yang semuanya telah bernuansa Islami.

\section{SIMPULAN}

Berdasarkan pembahasan tersebut ini, penulis mengambil kesimpulan sebagai berikut:

1. Kehadiran Islam ke nusantara tidak lepas dari nuansa di mana Islam itu lahir. Akan tetapi, Islam mampu beradaptasi dengan kebudayaan lokal. Proses persenyawaan keislaman dengan kenusantaraan, menjadikan Islam yang ada di nusantara ini, mudah diterima oleh masyarakat. Tidak ada resistensi, yang ada adalah penyambutan. Sungguhpun ada modifikasi, itu tidak lebih pada injeksi nilai-nilai keislaman dalam tradisi yang telah ada. Dalam perkembangannya, Islam nusan- 
tara dengan wataknya yang moderat dan apresiatif terhadap budaya lokal, serta memihak warga setempat dalam menghadapi tantangan, menyebabkan Islam diterima sebagai agama baru.

2. Bukti nyata dari proses persenyawaan antara Islam dan budaya lokal, dapat ditemukan dalam bentuk karya Babad, hikayat, lontara, sastra suluk, mitologi. Kemudian dari segi bentuk arsitektur bangunan-bangunan atap masjid Demak yang berlapis sembilan "dari Meru" pra Islam, kemudian diganti oleh Sunan Kalijaga menjadi tiga yang melambangkan Iman, Islam, dan Ihsan. Budaya selamatan, Maulid Nabi, Yasinan, Sekaten.

\section{CATATAN AKHIR:}

1. Setelah Nabi Muhammad saw. wafat, masyarakat terus berkembang, masalah baru terus berkembang dan bermunculan dengan tiada akhirnya, sementara wahyu Allah dalam bentuk Alquran dan al-Sunnah telah berakhir setelah beliau wafat. Sedang agama yang memasuki zaman, situasi sosial dan kulturalnya berbeda dengan situasi tempat berdirinya, maka agama itu pasti menghadapi problematika baru. Jika ia mempertahankan autentisitasnya sesuai dengan aslinya sebagaimana yang dibawa oleh pendirinya sepanjang masa, dari masa ke masa dalam pagar kepranataan yang tidak tembus oleh pemikiran baru, maka charisma agama itu tidak tersentuh dan tidak akan berkembang. Lihat: Said Agil Husin al-Munawar, Al-Qur'an Membangun Tradisi Kesalehan Hakiki (Cet. III; Jakarta: Ciputat Press, 2003), h. 287-288.

2. Jaih Mubarok, Sejarah Peradaban Islam (Cet. I; Bandung: Pustaka Islamika, 2008), h. 275-276.

3. Lihat: Shāfī al-Raḥmān al-Mubār Kafūrī, al-Rahīi al-Makhtūm: Bahles fì al-Sīrah alNabawiyyah 'alā Shahibihā Afadal al-Shalah wa al-Salām (Cet. XXI; Mesir: Dār al-Wafā, 2010), h. 21. Lihat pula: Hamilton A. R. Gibb, Studies on The Civilization of Islam (USA: Beacon Press, 1962), h. 3.

4. Lihat: 'Umar 'Abd al-Jabbār, Khulāshah Nūr al-Yaqin fì Sìrah Sayyid al-Mursalīn (Surabaya: Sālim Nabhān, t. th.), h. 5. Lihat pula: Nurcholish Madjid, Islam Doktrin dan Peradaban (Cet. I; Jakarta: Paramadina, 1992), h. 425.

5. Departemen Agama Republik Indonesia, Al-Qur'an dan Terjemahnya (Semarang: Toha Putra, 2007), h. 461.

6. Ibid., h. 502.

7. Lihat: M. Quraish Shihab, Membumikan Al-Quran:Fungsi dan Peran Wahyu dalam Kehidupan Masyarakat (Cet. I; Bandung: Mizan, 2007), h. 330-331.

8. Sebab, betapapun universalnya suatu ajaran, jika dikemas secara tekstual, apalagi jika berlabel agama, niscaya akan berubah menjadi parsial dan eksklusif yang justru akan mengaburkan makna universalitas agama itu sendiri. Lihat: Hamka, Islam: Rahmah untuk Bangsa (Cet. I; Jakarta: Wahana Semesta Intermedia, 2009), h. 29-31.

9. M. Dawam Rahardjo, Paradigma Al-Quran: Metodologi Tafsir dan Kritik Sosial (Cet. I; Jakarta: PSAP Muhammadiyah, 2005), h. 132-133.

10. Lihat: Bruce Lawrence, The Quran: A Biography, diterj. Aditya Hadi Pratama, Al-Qur'an: Sebuah Biografi (Cet. I; Bandung: Semesta Inspirasi, 2008), h. 2-4.

11. Muhammad Hari Zamharir, Agama dan Negara: Analisis Kritis Pemikiran Politik Nurcholish Madjid (Cet. I; Jakarta: RajaGrafindo Persada, 2004), h. 175.

12. Tim Penyusun Kamus Pusat Pengembangan dan Pembinaan Bahasa, Kamus Besar Bahasa Indonesia (Cet. II; Jakarta: Balai Pustaka, 1990), h. 134. 
13. Lihat: Hamka, Sejarah Umat Islam IV (Cet. III; Jakarta: Bulan Bintang, 1981), h. 25-30.

14. Lihat: Badri Yatim, Sejarah Peradaban Islam (Cet. XIX; Jakarta: RajaGrafindo Persada, 2007), h. 214-216.

15. Sultan Agung, nama lengkapnya Sultan Agung Hanyakrakusuma Senapati Ing Ngalaga Ngabdurrahman. Nama kecilnya Raden Mas Rangsang. Ayahnya Prabu Anyakrawati (Raden Mas Jolang), raja Mataram kedua. Ibunya bernama Ratu Mas Adi, putri Pangeran Benawa dari Pajang. Lihat: Tim Penulis IAIN Syarif Hidayatullah, Ensiklopedi Islam Indonesia Jilid I (Cet. II; Jakarta: Djambatan, 2002), h. 41-42.

16. Hasan Muarif Ambary, et al., Ensiklopedi Indonesia (Cet. IX; Jakarta: Ichtiar Baru van Hoeve, 2003), h. 165-166.

17. Tim Penulis IAIN Syarif Hidayatullah, loc. cit.

18. Kuntowijoyo, Paradigma Islam: Interpretasi untuk Aksi (Bandung: Mizan, 2008), h. 386.

19. Sultan adalah gelar yang dipakai para penguasa muslim secara resmi sejak abad ke-11 (abad ke-5 H). Kata Sultan merupakan derivasi dari kata kerja salata yang berarti menguasai atau memimpin. Lihat: ibid. Lihat pula: Tim Penulis IAIN Syarif Hidayatullah, Ensiklopedi Islam Indonesia Jilid 3, O - Z (Cet. II; Jakarta: Djambatan, 2002), h. 1068.

20. Susuhunan artinya orang yang dihormati. Kata susuhunan sama dengan gelar panembahan. Lihat: Soekama Karya, et al., Ensiklopedi Mini Sejarah dan Kebudayaan Islam (Cet. II; Jakarta: Logos Wacana Ilmu, 1998), h. 212.

21. Taufik Abdullah, et al., Sejarah Ummat Islam Indonesia (Cet. I; Jakarta: Majelis Ulama Indonesia, 1991), h. 118.

22. Ibid.

23. Kuntowijoyo, loc. cit.

24. Ibid. h. 387.

25. Ibid., h. 389.

26. Ibid., h. 391.

27. Ibid., h. 395 .

28. Ibid. h. 394.

29. Lihat: Moeslim Abdurrahman, Islam sebagai Kritik Sosial (Cet. I; Jakarta: Erlangga, 2003), h. 151-152.

DAFTAR PUSTAKA:

'Abd al-Jabbār, Umar. Khulāshah Nūr al-Yaqīn fì Sìrah Sayyid al-Mursalīn. Surabaya: Sālim Nabhān, t. th.

Abdullah, Taufik. et al. Sejarah Ummat Islam Indonesia. Cet. I; Jakarta: Majelis Ulama Indonesia, 1991.

Abdurrahman, Moeslim. Islam sebagai Kritik Sosial.Cet. I; Jakarta: Erlangga, 2003.

Ambary, Hasan Muarif, et al. Ensiklopedi Indonesia. Cet. IX; Jakarta: Ichtiar Baru van Hoeve, 2003.

Departemen Agama Republik Indonesia. Al-Qur'an dan Terjemahnya. Semarang: Toha Putra, 2007.

Gibb, Hamilton A. R. Studies on The Civilization of Islam. USA: Beacon Press, 1962.

Hamka, Sejarah Umat Islam IV. Cet. III; Jakarta: Bulan Bintang, 1981.

Haq, Hamka. Islam: Rahmah untuk Bangsa. Cet. I; Jakarta: Wahana Semesta Intermedia, 2009.

Kafūrī, Shāfī al-Raḥmān al-Mubār. al-Rah̄ì al-Makhtūm: Bahnts fĩ al-Sīrah al-Nabawiyyah 'alā Shahibihā Afadal al-Shalah wa al-Salām. Cet. XXI; Mesir: Dār al-Wafā, 2010.

Karya, Soekama, et al. Ensiklopedi Mini Sejarah dan Kebudayaan Islam. Cet. II; Jakarta: Logos Wacana Ilmu, 1998. 
Kuntowijoyo. Paradigma Islam: Interpretasi untuk Aksi. Cet. I; Bandung: Mizan, 2008.

Lawrence, Bruce. The Quran: A Biography, diterj. Aditya Hadi Pratama, Al-Qur'an: Sebuah Biografi. Cet. I; Bandung: Semesta Inspirasi, 2008.

Madjid, Nurcholish. Islam Doktrin dan Peradaban. Cet. I; Jakarta: Paramadina, 1992.

Mubarok, Jaih. Sejarah Peradaban Islam. Cet. I; Bandung: Pustaka Islamika, 2008.

Al-Munawar, Said Agil Husin. Al-Qur'an Membangun Tradisi Kesalehan Hakiki. Cet. III; Jakarta: Ciputat Press, 2003.

Rahardjo, M. Dawam. Paradigma Al-Quran: Metodologi Tafsir dan Kritik Sosial. Cet. I; Jakarta: PSAP Muhammadiyah, 2005.

Shihab, M. Quraish. Membumikan Al-Quran:Fungsi dan Peran Wahyu dalam Kehidupan Masyarakat. Cet. I; Bandung: Mizan, 2007.

Tim Penulis IAIN Syarif Hidayatullah. Ensiklopedi Islam Indonesia Jilid I. Cet. II; Jakarta: Djambatan, 2002.

Tim Penulis IAIN Syarif Hidayatullah. Ensiklopedi Islam Indonesia Jilid 3, O - Z. Cet. II; Jakarta: Djambatan, 2002.

Tim Penyusun Kamus Pusat Pengembangan dan Pembinaan Bahasa. Kamus Besar Bahasa Indonesia (Cet. II; Jakarta: Balai Pustaka, 1990.

Yatim, Badri. Sejarah Peradaban Islam. Cet. XIX; Jakarta: RajaGrafindo Persada, 2007.

Zamharir, Muhammad Hari. Agama dan Negara: Analisis Kritis Pemikiran Politik Nurcholish Madjid. Cet. I; Jakarta: RajaGrafindo Persada, 2004. 